UC. 10

$L A--9155-11 S$

Issued: January 1982

DE82 008898

\title{
Solvent Extraction of Thorium from \\ Nitrate Solutions by \\ Dibutyl Butylphosphonate in Isopar $\mathbf{H}$
}

\author{
Jerry E. Freer \\ Daniel H. Crump \\ Keith M. Axler \\ David G. Clifton \\ Sidney W. Hayter \\ Clifford W. Mills
}

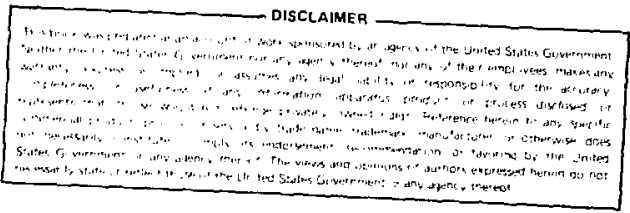

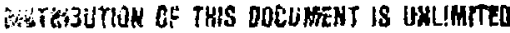


SOLVENT EXTRACTION OF THORIUM FROM NITRATE SOLUTIONS

BY DIBUTYL BUTYLPHOSPHONATE IN ISOPAR $\mathrm{H}$

by

Jerry E. Freer, Daniel H. Crump, Keith M. Axler, David G. Clifton, Sidney W. Hayter, and Clifford W. Mills

\section{ABSTRACT}

Solvent extraction of thoriun by 30 vcl\% dibutyl butylphosphonate-70 vol\% Isopar $H$ from salted and nonsalted nitric acid solutions was studied.

Thorium distribution coefficients $D_{\text {Th }}$ 's were obtained for nitric acid solutions of $\sim 0.3$ to $\sim 12 \underline{N}$ and for solutions of 1 and $2 \underline{\mathrm{M}} \mathrm{NH}_{4} \mathrm{NO}_{3}$ over the $\mathrm{HNO}_{3}$ concentration range of $\sim 0.5$ to $\sim 9 \underline{\mathrm{N}}$.

The nitric acid solution $\mathrm{D}_{\mathrm{Th}}$ 's varied from $\sim 4.3$ at the lowest acidity, increased to a maximum of $\sim 40$ at $\sim 3-4 \underline{\mathrm{N}} \mathrm{H}^{+}$, and then gradually decreased to $\sim 18$ at $\sim 11.5 \underline{\mathrm{N} \mathrm{H}}{ }^{+}$.

The solutions containing 1 and $2 \underline{\mathrm{M}} \mathrm{NH}_{4} \mathrm{NO}_{3}$ gave definite "salting-out effects" with $\mathrm{D}_{\mathrm{Th}}$ 's of 79 to 90, respectively, at the lowest acidities; these values then decreased with acidity increases to those of the nonsalted acid solutions at $\sim 5 \mathrm{~N}$ $\mathrm{HNO}_{3}$ and paralleled the acid solution values up to $\sim 12$ N. 


\section{SOLVENT SYSTEM}

The extracting solvent system used was dibutyl butylphosphonate (DBBP) in the diluent Isopar H (I). Fresh 30 vol\% DBBP-70 vol\% I solvent was used for the bulk of the extractions reported; however, three tests are reported for fresh solvent systems of 15, 10, and 5 vol\% DBBP. These were done at a nominal feed acidity of $\sim 4 \mathrm{~N}_{\mathrm{HNO}_{3}}$ that represented the acid range for the maximum extraction found for the 30 vol\% DBBP system.

\section{FEED SOLUTIONS}

A stock solution of 1-liter volume containing $0.353 \mathrm{Mh}\left(\mathrm{NO}_{3}\right)_{4}$ and $0.5 \underline{\mathrm{N}}$ $\mathrm{HNO}_{3}$ was prepared. Aliquots assayed for $\mathrm{ThO}_{2}$ gave a value within $\sim 1.1 \%$ of that calculated from the weight of $\mathrm{Th}\left(\mathrm{NO}_{3}\right)_{4} \cdot 4 \mathrm{H}_{2} \mathrm{O}$ added.

Extraction test feed soiutions were made by pipetting an aliquot (generally $25 \mathrm{ml}$ ) of the stock solution into a 100-ml volumetric flask, then adding the appropriate amounts of concentrated $\mathrm{HNO}_{3}$ and $\mathrm{NH}_{4} \mathrm{NO}_{3}$ so that final $\mathrm{H}_{2} \mathrm{O}$ dilution to $100 \mathrm{~m} \ell$ gave the feed of the desired concentrations.

Feed solutions covered the following ranges.

(1) $0.088 \quad \mathrm{M} \mathrm{Th}^{+4}$ solutions with no $\mathrm{NH}_{4} \mathrm{NO}_{3}$ and $\mathrm{HNO}_{3}$ from -0.3 to $12 \underline{\mathrm{N}}$.

(2) $0.088 \mathrm{Mh}^{{ }^{4}}$ solutions $1 \mathrm{M}$ in $\mathrm{NH}_{4} \mathrm{NO}_{3}$ with $\mathrm{HNO}_{3}$ from $\sim 0.5$ to $5.75 \underline{\mathrm{N}}$.

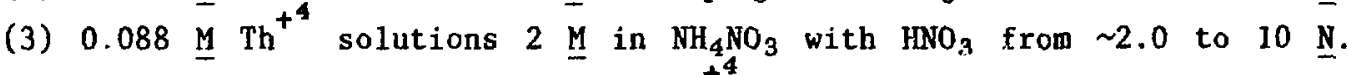

(4) Some additional solutions with $\mathrm{Th}^{+^{4}}$ varying from $\sim 0.35 \underline{\mathrm{M}}$ to $\sim 0.04 \underline{\mathrm{M}}$ as listed in the tabulated data.

III. EXTRACTION AND STRIPPING PROCEDURES

Solvent $(25 \mathrm{ml})$ was measured out and placed into a 125 -ml separatory funnel with an equal amount of the desired feed solution. This solvent-to-feed ratio of $1: 1$ was used throughout the tests.

The stoppered funnel was shaken for 3 to 5 minutes, allowed to settle, and then the aqueous raffinate phase was drawn off into a stoppered bottle. The organic phase was decanted from any residual aqueous phase. 
Previous exploratory stripping tests shrwed that the thorium could be stripped from the organic phase with two $50-\mathrm{ml}$ portions of $\mathrm{H}_{2} \mathrm{O}$ followed by a 25-me $\mathrm{H}_{2} \mathrm{O}$ strip. For the higher acidity feeds, another strip pass with $25 \mathrm{ml}$ of $\mathrm{H}_{2} \mathrm{O}$ was necessary. All strip-passes were kept separated and then were assayed for $\mathrm{ThO}_{2}$ as was the raffinate.

IV. THORIUM DETERMINATIONS AND $\mathrm{H}^{*}$ TITRATIONS

Aliquots of each strip and raffinate were pipected into tared crucibles. These were tiken to dryness slowly on a hot plate set at low heat to prevent splattering. Next, they were placed in a muffle furnace and slowly taken to $600^{\circ} \mathrm{C}$ or higher and held for 30 minutes or more. This decomposes the solids leaving a $\mathrm{ThO}_{2}$ residue. After cooling, the weight of $\mathrm{ThO}_{2}$ was obtained.

A mass balance was then struck with the sums of the $\mathrm{ThO}_{2}$ values for the strips and raftinate as compared with that previously found in the feed. The balances for all reported tests agreed to $3.5 \%$ or better.

These results are tabulated in Tables $I$ and $I I$.

The equilibrium aqueous phase $\mathrm{H}^{+}$concentration was determined by taking an appropriate aliquot of the raffinate and titrating with a standard NaOH solution (either 0.1 or $1.0 \mathrm{~N}$ ) to a methyl-orange end point. Additions of $\mathrm{H}_{2} \mathrm{O}$ and $\sim 15-30$ $\mathrm{ml}$ of $2 \mathrm{M} \mathrm{KF}$ were made before titration to prevent the hydrolysis of the $\mathrm{Th}^{+4}$ during titration. Experimental results are listed in Tables $I$ and II.

\section{DISTRIBUTION COEFFICIENTS ( $\left.\mathrm{D}_{\mathrm{Th}}\right)$}

The distribution coefficient $D_{T h}$ is defined as the concentration of thorium in the organic phase divided by its concentration in the aqueous phase when the two phases are in equilibrium. Therefore, these were calculated by dividing the total $\mathrm{ThO}_{2}$ obtained in the strips by that obtained for the raffinate because these experiments used organic-to-feed volumes of $1: 1$.

The obtained $D_{T h}$ 's are given in Tables $I$ and II. 
TABLE I

Th EXTRACTIONS WITH 30 Vol\% DBBP-- 70 Vol\% ISOPAR H

\begin{tabular}{|c|c|c|c|c|c|c|c|c|c|c|}
\hline $\begin{array}{l}\text { Ext raction } \\
\text { Test } \\
\text { XT }\end{array}$ & $\begin{array}{l}\text { Feed, } \\
\text { Nominal } \\
{\left[\mathrm{HHO}_{3}\right] \text {, }} \\
\underline{\mathrm{N}}\end{array}$ & $\begin{array}{c}\text { Equilibrius } \\
\text { Aqueous } \\
{[\mathrm{H}+]} \\
\mathrm{H}\end{array}$ & $\begin{array}{c}\text { Feed, } \\
{\left[\mathrm{Th}^{\left.\left(\mathrm{MO}_{3}\right)_{4}\right]}\right.} \\
\underline{\mathrm{M}}\end{array}$ & $\begin{array}{c}\text { Feed, } \\
{\left[\begin{array}{c}\left.\mathrm{NH}_{4} \mathrm{NO}_{3}\right] \\
\underline{M}\end{array}\right]}\end{array}$ & $\begin{array}{l}\text { Raffinate } \\
\text { Tho } 0_{2}, 8\end{array}$ & $\begin{array}{c}\text { Total } \\
\text { Strip } \\
\text { ThO }_{2}, \mathrm{~B}\end{array}$ & $\begin{array}{l}\text { Faffinate } \\
\mathrm{Plus} \mathrm{Strip} \\
\mathrm{ThO}_{2}, \mathrm{~B}\end{array}$ & $\begin{array}{l}\text { Feed, } \\
\mathrm{ThO}_{2}, 8\end{array}$ & $\begin{array}{c}\text { \% Deviation } \\
\text { from Mass } \\
\text { Balance }\end{array}$ & $\mathrm{D}_{T h}$ \\
\hline $\begin{array}{r}28 \\
14 \\
16 \\
17 \\
13 \\
4 \\
9 \\
5 \\
19 \\
18 \\
12 \\
24 \\
27\end{array}$ & $\begin{array}{l}0.3 \\
0.5 \\
0.9 \\
1.0 \\
1.25 \\
2.0 \\
4.0 \\
6.0 \\
6.5 \\
7.5 \\
8.0 \\
11.2 \\
12.0\end{array}$ & $\begin{array}{l}0.25 \\
0.41 \\
0.72 \\
0.78 \\
1.0 \\
1.5 \\
2.97 \\
5.1 \\
5.8 \\
6.7 \\
6.8 \\
10.5 \\
11.6\end{array}$ & $\begin{array}{l}0.088 \\
0.088 \\
0.088 \\
0.088 \\
0.088 \\
0.088 \\
0.088 \\
0.088 \\
0.088 \\
0.088 \\
0.088 \\
0.088 \\
0.088\end{array}$ & & $\begin{array}{l}c .1103 \\
0.0788 \\
0.0410 \\
0.0375 \\
0.0273 \\
0.0198 \\
0.0143 \\
0.0135 \\
0.0200 \\
0.0235 \\
0.0195 \\
0.0233 \\
0.0298\end{array}$ & $\begin{array}{l}0.4765 \\
0.5100 \\
0.5445 \\
0.5398 \\
0.5660 \\
0.5698 \\
0.5753 \\
0.5643 \\
0.5603 \\
0.5558 \\
0.5517 \\
0.5615 \\
0.5568\end{array}$ & $\begin{array}{l}0.587 \\
0.589 \\
0.586 \\
0.577 \\
0.593 \\
0.590 \\
0.590 \\
0.578 \\
0.580 \\
0.579 \\
0.571 \\
0.585 \\
0.587\end{array}$ & $\begin{array}{l}0.583 \\
0.583 \\
0.583 \\
0.583 \\
0.583 \\
0.583 \\
0.583 \\
0.583 \\
0.583 \\
0.583 \\
0.583 \\
0.583 \\
0.583\end{array}$ & $\begin{array}{l}0.7 \\
1.0 \\
0.5 \\
1.0 \\
1.8 \\
1.1 \\
1.1 \\
0.9 \\
0.5 \\
0.6 \\
2.0 \\
0.3 \\
0.6\end{array}$ & $\begin{array}{r}4.3 \\
6.5 \\
13.3 \\
14.4 \\
20.8 \\
29.0 \\
40.0 \\
42.0 \\
28.0 \\
24.0 \\
28.0 \\
24.0 \\
19.0\end{array}$ \\
\hline $\begin{array}{l}22 \\
15 \\
21 \\
20 \\
29\end{array}$ & $\begin{array}{l}0.5 \\
0.5 \\
2.0 \\
3.0 \\
5.75\end{array}$ & $\begin{array}{l}0.36 \\
0.39 \\
1.5 \\
2.35 \\
4.9\end{array}$ & $\begin{array}{l}0.088 \\
0.088 \\
0.088 \\
0.088 \\
0.088\end{array}$ & $\begin{array}{l}1.0 \\
1.0 \\
1.0 \\
1.0 \\
1.0\end{array}$ & $\begin{array}{l}0.0073 \\
0.0105 \\
0.0108 \\
0.012 \\
0.0145\end{array}$ & $\begin{array}{l}0.5708 \\
0.5783 \\
0.5665 \\
0.5695 \\
0.5733\end{array}$ & $\begin{array}{l}0.578 \\
0.589 \\
0.577 \\
0.582 \\
0.588\end{array}$ & $\begin{array}{l}0.583 \\
0.583 \\
0.583 \\
0.583 \\
0.583\end{array}$ & $\begin{array}{l}0.5 \\
1.0 \\
1.0 \\
0.2 \\
0.8\end{array}$ & $\begin{array}{l}79.0 \\
55.0 \\
53.0 \\
47.0 \\
40.0\end{array}$ \\
\hline $7^{2}$ & 1.0 & 0.82 & 0.044 & 1.0 & 0.0036 & 0.2643 & 0.268 & 0.290 & 7.5 & 73.0 \\
\hline $\begin{array}{r}1 \\
2 \\
10 \\
26 \\
23 \\
25\end{array}$ & $\begin{array}{l}2.0 \\
2.0 \\
4.0 \\
4.5 \\
6.0 \\
9.9\end{array}$ & $\begin{array}{l}1.7 \\
1.72 \\
3.1 \\
3.7 \\
5.2 \\
9.4\end{array}$ & $\begin{array}{l}0.08 \\
0.08 \\
0.088 \\
0.088 \\
0.088 \\
0.088\end{array}$ & $\begin{array}{l}2.0 \\
2.0 \\
2.0 \\
2.0 \\
2.0 \\
2.0\end{array}$ & $\begin{array}{l}0.0058 \\
0.0068 \\
0.0080 \\
0.0113 \\
0.0163 \\
0.0329\end{array}$ & $\begin{array}{l}0.5173 \\
0.5206 \\
0.5635 \\
0.5518 \\
0.5580 \\
0.5475\end{array}$ & $\begin{array}{l}0.523 \\
0.527 \\
0.572 \\
0.563 \\
0.574 \\
0.580\end{array}$ & $\begin{array}{l}0.528 \\
0.528 \\
0.583 \\
0.583 \\
0.583 \\
0.583\end{array}$ & $\begin{array}{l}0.9 \\
0.2 \\
1.9 \\
3.4 \\
1.5 \\
0.5\end{array}$ & $\begin{array}{l}89.0 \\
77.0 \\
70.0 \\
49.0 \\
34.0 \\
17.0\end{array}$ \\
\hline
\end{tabular}

${ }^{3}$ These data points are not plotted on Fig. 1.

TABLE II

Th EXTRACTIONS WITH 30 vol\% DBBP -70 vol\% ISOPAR H

\begin{tabular}{|c|c|c|c|c|c|c|c|c|c|c|}
\hline $\begin{array}{l}\text { Extraction } \\
\text { Test } \\
\text { XT }\end{array}$ & $\begin{array}{l}\text { vol\% } \\
\text { DBE? }\end{array}$ & $\begin{array}{l}\text { Feed, } \\
\text { Nominil } \\
{\left[\mathrm{WNO}_{3}\right] \text {, }} \\
\mathbb{N}\end{array}$ & $\begin{array}{c}\text { Equilibriú } \\
\text { Aqueous } \\
{\left[\begin{array}{l}\mathrm{H}+] \\
\underline{u}\end{array}\right.}\end{array}$ & $\begin{array}{c}\text { Feed, } \\
\left.[\underset{\underline{H}}{[\mathrm{TO}})_{4}\right]\end{array}$ & $\begin{array}{l}\text { Raffinate, } \\
{\left[\mathrm{ThO}_{2}\right], 8} \\
\underline{\mathrm{H}}\end{array}$ & $\begin{array}{l}\text { Total } \\
\text { Strip } \\
\text { ThO } 2,8\end{array}$ & $\begin{array}{l}\text { Raffinate } \\
\text { Plus Strip } \\
\mathrm{ThO}_{2}, \mathrm{~g}\end{array}$ & $\begin{array}{l}\text { Feed, } \\
\text { Th0 }, 8\end{array}$ & $\begin{array}{l}\text { Theviation } \\
\text { frow Haks } \\
\text { Balasce }\end{array}$ & $D_{\mathrm{Th}}$ \\
\hline 9 & 30 & 4.0 & 3.0 & 0.088 & 0.0143 & 0.5753 & 0.590 & 0.583 & 1.1 & 40.0 \\
\hline 30 & 15 & 4.0 & 3.4 & 0.088 & 0.0800 & 0.5096 & 0.590 & 0.583 & 1.1 & 6.4 \\
\hline 31 & 10 & 4.0 & 3.3 & 0.088 & 0.2028 & 0.3948 & 0.598 & 0.583 & 2.5 & 2.0 \\
\hline 32 & 5 & 4.0 & 3.5 & 0.088 & 0.4130 & 0.1857 & 0.559 & 0.583 & 2.7 & 0.45 \\
\hline
\end{tabular}


The Table I data for all feed solutions containing $\sim 0.088 \mathrm{M} \mathrm{Th}^{+4}$ are plotted in Fig. 1 as $D_{\text {Th }}$ versus the equilibrium aqueous phase acidity. Note that these data are for 30 vol\% DBBP-70 vol\% $I$. The data points of Table I that apply to $\mathrm{Th}^{+4}$ concentrations other than the above values are not shown in Fig. 1 because they clutter the figure. Examination of these points, however, showis that as the $\mathrm{Th}^{+4}$ concentration decreases to $\sim 0.04 \underline{\mathrm{M}}$ for solutions similar to the $0.088 \mathrm{M}$ cases the $\mathrm{D}_{\mathrm{Th}}$ is higher; whereas, for the one case of $0.349 \mathrm{M} \mathrm{Th}^{+4}$, the $\mathrm{D}_{\mathrm{Th}}$ is depressed.

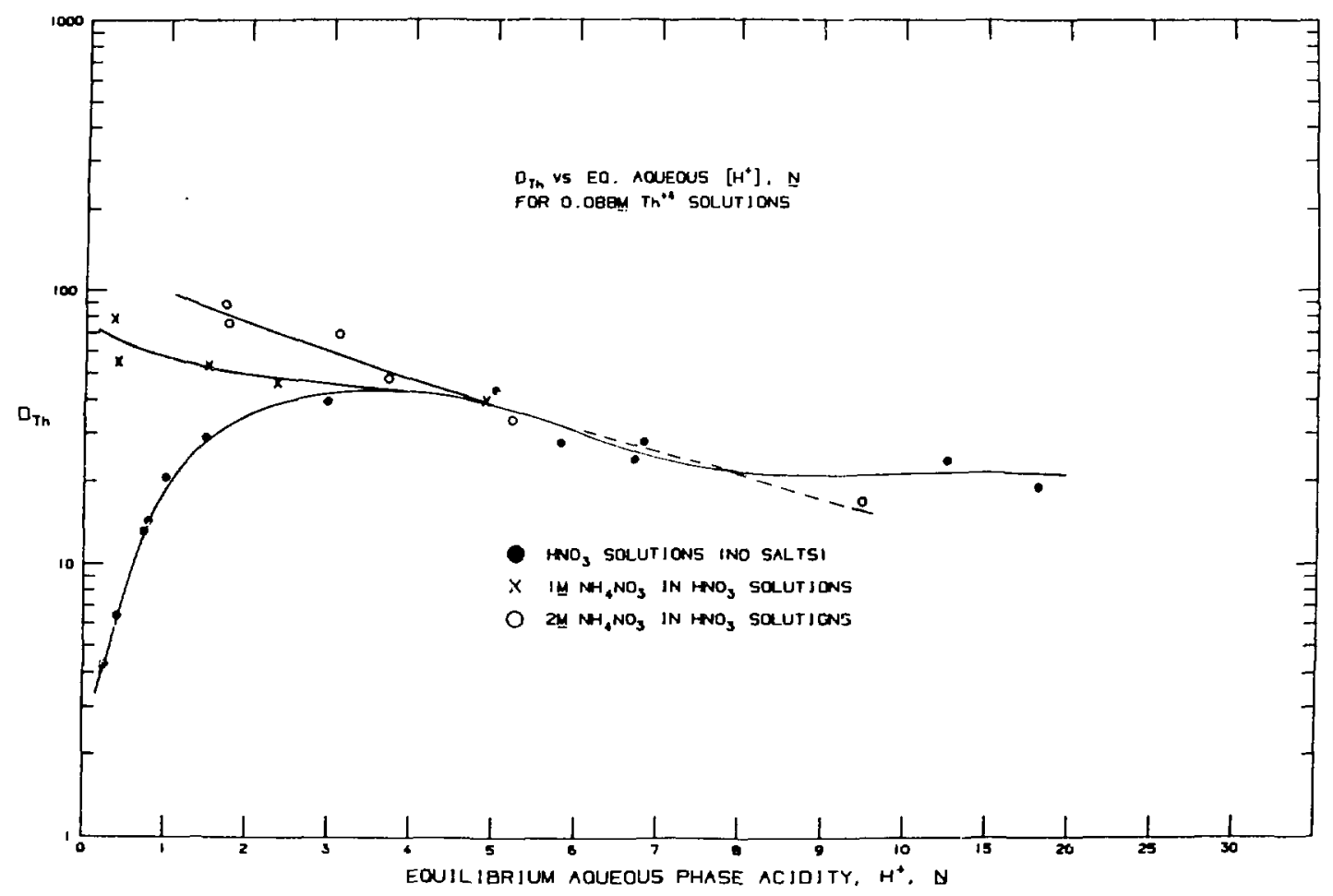

Fig. 1. $\mathrm{D}_{\mathrm{Th}}$ Eq. Aqueous $\left[\mathrm{H}^{+}\right], \underline{N}$

The Table II data are given in Fig. 2. Here a $\log -\log$ plot is given of $D_{T h}$ versus vol\% DBBP in Isopar $H$. The line struck through these points has a slope of 2.5, indicating a dependency of $\mathrm{D}_{\mathrm{Th}}$ upon the DBBP concentration of between two and three; therefore, these data do not establish whether the extractable complex contains two or three molecules of DBBP. 


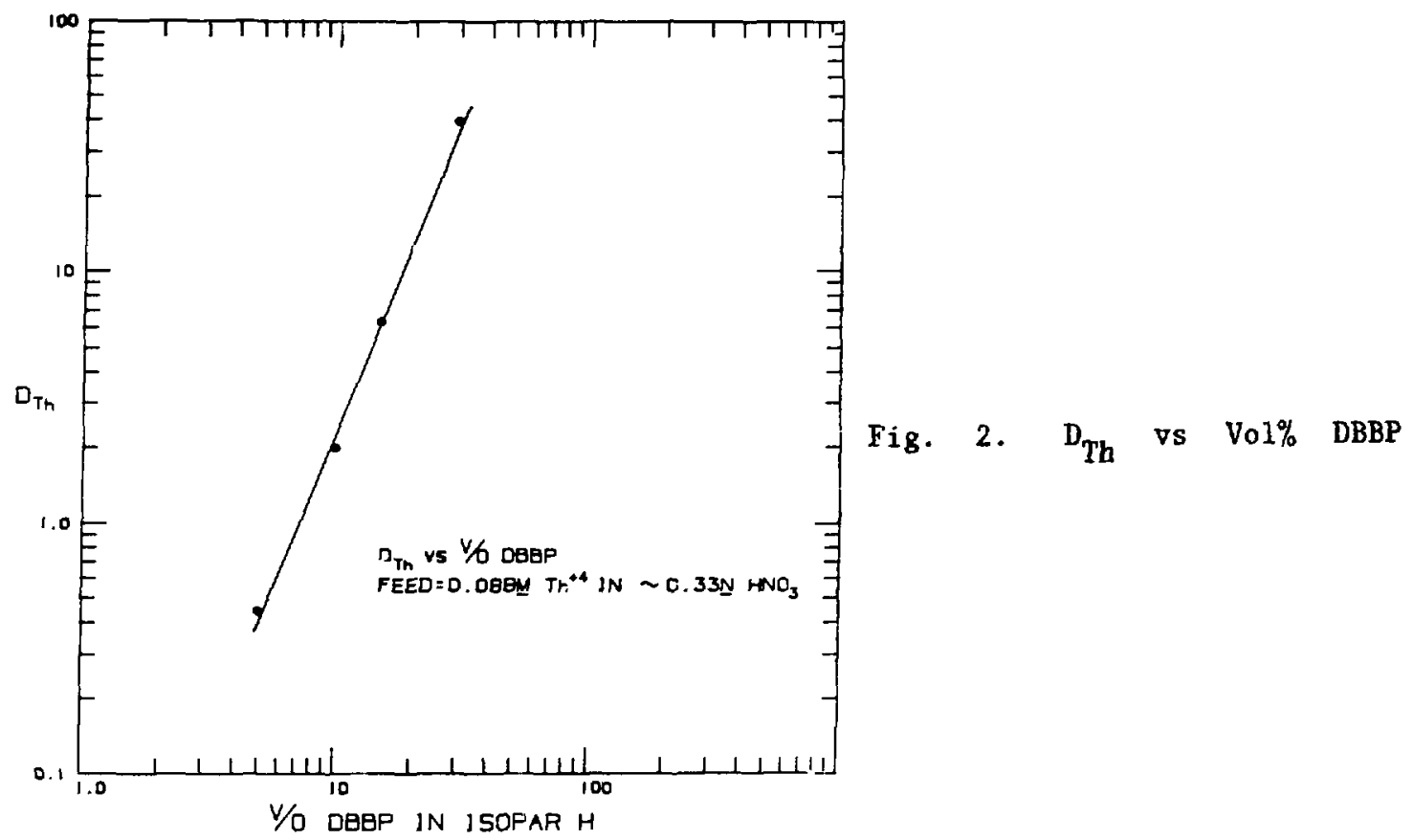

VI. CONCLUSIONS

Figure 1 shows that for unsalted $\mathrm{HNO}_{3}$ solutions, the $\mathrm{D}_{\mathrm{Th}}$ values for 30 vol\% DBBP-70 vol\% I go through a maximum of $\sim 43$ between $\sim 3$ to 5 in $\mathrm{HNO}_{3}$ anó has a value of $\sim 4$ at the lowest acidity studied; that is, $\sim 0.25 \underline{\mathrm{N}} \mathrm{H}^{+}$. At low acidities, adding 1 or $2 \underline{\mathrm{M}}$ of $\mathrm{NH}_{4} \mathrm{NO}_{3}$ gives a "salting-out effect," increasing the $D_{T h}$ to values between $\sim 50$ to 100 . This enhancement of $\mathrm{D}_{\mathrm{Th}}$ decreases as the acidity increases until the salting-out effect is essentially gone from $\sim 5 \mathrm{~N}^{+}$upward.

From the data obtajned for variable DBBP concentrations in Isopar $H$, as shown in Fig. 2, we see that for solutions $\sim 3.3 \mathrm{~N}$ in $\mathrm{HNO}_{3}$ and containing $\sim 0.088 \mathrm{M} \mathrm{Th}^{+4}$, the $\mathrm{D}_{\mathrm{Th}}$ values vary as the 2.5 power of the DBBP concentration. 